\title{
Feira Cultural e Científica: Brasil e Estados Unidos
}

\author{
Feria Cultural y Científica: Brasil y Estados Unidos \\ Cultural and Scientific Fair: Brazil and the United States
}

\author{
Eliana Martins Marcolino ${ }^{1}$ \\ Carlos José Cartaxo ${ }^{2}$
}

\begin{abstract}
Resumo
O presente artigo é o relato de experiência da primeira Feira Cultural e Científica Brasil e Estados Unidos, realizada entre os dias 02 a 05 de novembro de 2017 em Framingham (Massachusetts), nos EUA. O objetivo da feira foi fortalecer a cooperação cultural entre a comunidade brasileira nos Estados Unidos e a comunidade acadêmica americana, assim como proporcionar uma integração entre as comunidades acadêmicas brasileira e a americana compostas por professores e alunos, americanos e emigrantes. Neste artigo os autores descrevem as atividades que foram realizadas na feira e propõem uma reflexão a partir desta experiência. A maioria dos participantes elogiou a iniciativa, a qual foi destacada como muito enriquecedora para intercâmbio de conhecimentos, por outro lado destacam-se o workshop na Harvard e a visita técnica ao MIT (Massachusetts Institute of Technology). Muitos apontaram como ponto frágil a má distribuição do tempo, ficando o evento um pouco cansativo devido à quantidade de atividades realizadas, e sugeriram que o evento se repita de forma aprimorada.
\end{abstract}

Palavras-Chave: Cultura brasileira; emigrantes brasileiros; Brasil- Estados Unidos.

\section{Resumen}

El presente artículo es el relato de la experiencia de la Primera Feria Cultural y Científica Brasil y Estados Unidos, realizada entre los días 02 a 05 de noviembre de 2017 en Framingham (Massachusetts), Estados Unidos. El objetivo de la feria fue fortalecer la cooperación cultural entre la comunidad brasileña en Estados Unidos y la comunidad académica estadounidense, así como propiciar una integración entre la comunidad académica brasileña y la americana compuestas por profesores e alumnos, estadounidenses e enmigrantes. En este artículo los autores describen las actividades que se realizaron en la feria y proponen una reflexión a partir de esta experiencia. La mayoría de los participantes elogió la iniciativa, la cual fue destacada como muy enriquecedora para el intercambio de conocimientos, todavia se destacam el taller en la Harvard y la visita técnica al MIT (Massachusetts Institute of Technology). Muchos señalaron como punto frágil la mala distribución del tiempo, quedando el evento un poco cansado debido a la cantidad de actividades realizadas, y sugirieron que el evento se repita de forma mejorada.

Palabras clave: Cultura brasileña; emigrantes brasileños; Brasil; Estados Unidos.

\begin{abstract}
This article is the experience report of the first Cultural and Scientific Fair Brazil and the United States, held from November 02 to 05, 2017 in Framingham (Massachusetts), USA. The purpose of the fair was to strengthen cultural cooperation between the Brazilian community in the United States and the American academic community, as well as to provide an integration between the Brazilian academic community and the American

\footnotetext{
1 Pós-Doutorado Júnior pela Fundação Oswaldo Cruz- Fiocruz. Doutora em Comunicação Social pela Universidade Metodista de São Paulo-Umesp. Professora do Mestrado em Gestão Integrada do Território da Universidade Vale do Rio Doce - Univale. Colaboradora do Cultural Agents Initiative, Harvard University. Emails: eliana.marcolino@univale.br/profaemarcolino@gmail.com.

2 Doutor em Artes Visuais e Educação pela Universidade de Barcelona. Professor Titular do Departamento de Comunicação da Universidade Federal da Paraíba. Coordenação do Curso de Radialismo. Email: carloscartaxo@yahoo.com.br.
} 
composed of teachers and students, Americans and emmigrants. In this article the authors describe the activities that were held at the fair and propose a reflection from this experience. Most of the participants praised the initiative, which was highlighted as very enriching for the exchange of knowledge, highlighting the Harvard workshop and the technical visit to MIT (Massachusetts Institute of Technology). Many pointed to the poor distribution of time as a fragile point, making the event somewhat exhausting due to the amount of activities performed, and suggested that the event be repeated but in an improved way.

Keywords: Brazilian culture; Brazilian emigrants; Brazil- U.S.A.

\section{Introdução}

O projeto Feira Cultural e Científica: Brasil e Estados Unidos teve o objetivo de realizar um movimento cultural nos Estados Unidos acerca das representações culturais do território brasileiro e concomitantemente uma exposição sobre a cultura Norte Americana, para um intercâmbio de conhecimentos entre os estudantes e professores brasileiros, americanos e estudantes emigrantes. Na Feira Cultural apresentou-se parte das representações culturais brasileiras tais como: as festas folclóricas, as culinárias, as culturas religiosas e muitos outros tipos de manifestações culturais, fortalecendo ainda mais o processo de valorização dos costumes locais, colocando-os em diálogo com a cultura Norte-americana.

O evento realizou-se entre os dias 02 a 05 de novembro de 2017 na Universidade de Framingham - Massachusetts. O projeto foi coordenado pela professora Eliana Marcolino, da Universidade Vale do Rio Doce, Brasil, em parceria com a empresária Ilma Paixão, então diretora da Rede de Rádios Abr A Brasileira, de Framingham - MA. As instituições participantes foram: Framingham University, Harvard University, Consulado Geral do Brasil em Boston e Universidade Vale do Rio Doce, UNIVALE.

A Feira Cultural e Científica: Brasil-Estados Unidos teve como meta o fortalecimento e a cooperação cultural entre a comunidade brasileira nos Estados Unidos e a comunidade acadêmica americana.

O projeto se justifica pela importância social de compartilhar os aspectos culturais do território brasileiro com os jovens estudantes que vivem nos Estados Unidos. É sabido que muitos estudantes brasileiros e americanos, filhos de emigrantes, desconhecem as culturas do seu país de origem ou de origem de seus pais. Existem americanos brasileiros que ignoram o código linguístico português e a riqueza cultural do Brasil. Diante dessa realidade esta Feira Cultural teve o propósito de provocar uma reflexão sobre a importância do conhecimento e a valorização da cultura de um povo, em particular, a cultura do povo brasileiro. 
Por meio das diversas manifestações artísticas e culturais, a comunidade acadêmica foi convidada a refletir sobre a importância das culturas brasileiras, visto que o respeito e a admiração somente serão possíveis quando há o conhecimento; quando se conhece o outro se passa a respeitá-lo. Vivemos tempos difíceis quando a globalização permite o encontro de distintas culturas em um mesmo espaço, porém, este encontro muitas vezes é permeado por conflitos e esses surgem por causa da ignorância, ou seja, pelo desconhecimento, sendo assim, acreditamos que a universidade tem um papel relevante no sentido de produzir e disseminar o conhecimento da cultura.

\section{Metodologia do processo de produção}

A Feira Cultural e Científica: Brasil e Estados Unidos foi organizada por duas equipes: Uma estruturada em Framingham - MA, USA, administrada pela diretora da Rede de Rádios Abr A Brasileira, Ilma Paixão e outra equipe coordenada pela professora Eliana Marcolino, da Universidade Vale do Rio Doce - UNIVALE com o apoio do professor Luciano Flávio de Oliveira da Fundação Universidade Federal de Rondônia - UNIR.

\subsection{Etapas do processo nos Estados Unidos:}

A diretora da Rádio Abr A Brasileira ficou responsável por fazer um movimento junto à comunidade brasileira que vive nos Estados Unidos. A Rádio fez a mobilização convidando a comunidade a participar da Feira e realizou a campanha família solidária para receber os professores brasileiros em suas casas. Criou um quadro na rádio "Aqui tem mais Brasil” onde se falou sobre a riqueza cultural brasileira.

\subsection{Etapas do processo no Brasil:}

A professora Eliana Marcolino, da UNIVALE, e o professor Luciano Flávio de Oliveira, da UNIR, foram responsáveis por contatar os(as) professores(as) no Brasil. O perfil do(a) professor(a) seria preferencialmente dos departamentos de Comunicação e Artes, Sociologia e Antropologia de Universidades de cada Estado Brasileiro. Foi solicitado ao(à) professor(a) realizar uma pesquisa a respeito da cultura daquele Estado e a produção de um documentário sobre o melhor da cultura daquela unidade da federação. É importante salientar que tanto as Universidades Federais quanto as particulares foram convidadas, assim como instituições das Capitais e também do interior. $\mathrm{O}(\mathrm{A})$ professor(a) deveria estar disposto(a) a financiar a própria viagem, se não conseguisse apoio financeiro institucional. A contrapartida seria a possibilidade de contato com as universidades americanas para parcerias futuras. 


\section{Realização do evento}

A Feira Cultrual e Científica: Brasil Estados Unidos teve início, no dia 02 de novembro, com uma visita técnica ao State House, em Boston quando os(as) professores(as) tiveram a oportunidade de conhecer a casa legislativa do Estado de Massachusetts. Os (as) participantes puderam se encontrar com oito parlamentares norte-americanos. Foram separados em grupos regionais e cada equipe visitou os parlamentares que os esperavam. Um pedido foi feito aos políticos americanos, isto é, que eles pensem em projetos políticos que possam respeitar os direitos dos imigrantes, os quais realizam trabalhos de relevância social na comunidade norte-americana.

Após a visita ao State House, os(as) professores(as) seguiram para o Consulado Geral do Brasil em Boston; o grupo foi recebido pela Consulesa Geral e embaixadora brasileira, Glivânia Oliveira. Os participantes então conheceram a dinâmica de funcionamento do Consulado. Em roda de conversa, cada convidado fez uma breve apresentação sobre a sua formação acadêmica e atuação profissional no Brasil. Em seguida, a embaixadora fez um relato sobre as demandas da comunidade brasileira nos Estados Unidos, sendo a saúde do imigrante uma das questões mais preocupantes, principalmente a saúde mental com casos de depressão, síndrome do pânico. Tudo isso pode ser desencadeado pelo consumo excessivo de álcool e drogas. Tenha-se em mente ainda a violência intrafamiliar e o aumento de casos de suicídio na comunidade de imigrantes brasileiros nos Estados Unidos. Casos de brasileiros que chegam ao país com a Doença de Chagas e que não têm nenhuma forma de tratamento, já que é uma enfermidade pouco prevalente no território americano. A consulesa sinalizou a importância da união entre as universidades brasileiras e o Consulado para o enfrentamento desses problemas que foram pontuados.

Ao concluir a visita, o grupo foi convidado a ir à casa da consulesa para um jantar de confraternização. Essa atividade social foi importante para aproximar professores, pesquisadores, artistas, empresários e pessoas direta e indiretamente ligadas ao evento.

Num mundo de individualismo extremado dos sujeitos, fruto da condição pósmoderna em que vivemos, aproximar pessoas é um ato que leva a construir relações saudáveis. A distância geográfica que existe entre países muitas vezes é quebrada com a aproximação cultural. A compreensão de que os povos fazem parte de um mesmo universo cultural é enriquecida quando participamos e vivenciamos de momentos construtivos como foi o que a Feira Cultural e Científica: Brasil e Estados Unidos nos propiciou. A cultura 
híbrida é uma concepção de vida que se tornou realidade quando pensamos o mundo como um ninho plural, um celeiro humano de diversas raças e diferentes origens. A tese da cultura híbrida é do argentino Néstor García Cancline, professor da Universidade do México, que tem contribuído para reflexão contextual do mundo em que se vive sob a égide de uma condição pós-moderna.

O encontro foi muito enriquecedor e provocador de reflexões. Dando continuidade às atividades, no dia seguinte, 03 de novembro, foi realizada a abertura solene da feira na Universidade de Framingham-Massachusetts. Os(as) professores(as) brasileiros(as) prepararam estandes com artesanatos de cada região do Brasil para receberem a visita dos estudantes das escolas primárias e secundárias de Framingham, para um processo interativo entre as culturas brasileira e a norte-americana. Além da exposição, os(as) professores(as) ofereceram brindes aos convidados. Foi feita uma exibição do Hino Nacional Brasileiro e do Hino Nacional Americano cantados pela soprano Sandra Ferreira. Também houve oportunidade para apresentações musicais como as do músico Pedro Coelho, de Minas Gerais, e do músico e folclorista gaúcho Angelino Rogério, os quais animaram o evento. Concomitantemente às apresentações, o artista plástico Josafá Neves e a professora Lêda Gonçalves realizaram oficinas de artes plásticas com um grupo de alunos.

No mesmo dia, os(as) professores(as) foram ao Brazilian-American Center, BRACE, para um encontro com as crianças assistidas pela instituição. Os estudantes realizaram uma apresentação de poesias brasileiras, e recitaram a Canção do Exílio de Gonçalves Dias. No entretempo, os(as) professores(as) vindos(as) do Brasil fizeram uma mostra de documentários sobre as cinco Regiões brasileiras. Nesta mesma ocasião, o artista plástico Josafá Neves e a professora Lêda Gonçalves realizaram oficinas de artes plásticas com este grupo de estudantes.

A visita ao BRACE (Brazilian-American Center), que tem o seu foco na educação de apoio à comunidade imigrante, consolidou a compreensão de que o conhecimento e a fraternidade são elementos que devem andar juntos. Os Estados Unidos da América, assim como qualquer país do mundo, precisam de organizações sem fins lucrativos que deem suporte àqueles sujeitos sociais menos favorecidos. No caso, o BRACE é uma entidade filantrópica que foi criada em 2012, pelo Padre Volmar Scaravelli, com o nobre objetivo de acolher, assistir e promover todos os imigrantes sem distinção de nacionalidade, raça, idade, 
gênero ou religião. E o que é mais importante, preservando os valores e a identidade cultural de todos que por ela passam.

Nós, participantes da Feira Cultural e Científica: Brasil e Estados Unidos, fomos surpreendidos e somos agradecidos por partilharmos de atividades com uma entidade que oferece inúmeras ações de acolhimento, como por exemplo: cursos, reuniões, seminários, palestras e eventos que tenham o fim de instruir, educar, capacitar e entreter as pessoas, acolhendo e contribuindo para a integração destas na sociedade norte-americana, inclusive, quando necessário, com acompanhamento psicológico e de saúde, apoio de assistência jurídica, de acesso ao Consulado brasileiro, prática esportiva, oportunidade de empregos e moradia. Esse trabalho tem um valor de significativa importância porque é realizado nos Estados Unidos da América, mas tem o zelo e a responsabilidade de preservar a cultura e a identidade brasileiras por meio de suas tradições, língua, crenças religiosas e a dignidade cidadã.

Os dias se passavam e a cada novo evento os participantes tinham a oportunidade de somar novas experiências. No dia 04 de novembro, foi o momento da exibição dos documentários elaborados pelos professores brasileiros. Os vídeos versavam sobre o melhor do Brasil; cada professor apresentou o melhor do seu Estado. Neste sentido, foram várias as manifestações culturais representadas nos filmes. Ao todo, foram exibidos dez documentários, isto é, uma mostra do que há de melhor nas cinco Regiões do Brasil: Centro-Oeste, Nordeste, Norte, Sul e Sudeste.

Apresentação dos Estados brasileiros da Região Centro-Oeste e do Distrito Federal foi moderada por Luciana Maria Castrillon, psicóloga bilíngue certificada pelo estado de Massachusetts. Castrillon falou sobre a diversidade cultural brasileira; ela fez um discurso bem humorado e criativo e no mesmo ritmo passou para a apresentação dos documentários. Mato Grosso do Sul foi representado pela professora Rosângela Lieko Kato, da Universidade Federal de Mato Grosso do Sul. O Distrito Federal foi representado pelo artista plástico Josafá Neves, da TV Brasil, e pela professora Leda Gonçalves de Freitas, da Universidade Católica de Brasília- UCB.

Apresentação dos Estados brasileiros da Região Nordeste foi moderada por Rosabelli Coelho-Keyssar, gestora do Programa MIT-Brazil no Massachusetts Institute of Technology MIT. O Estado da Paraíba foi representado pelo professor Carlos José Cartaxo, da Universidade Federal da Paraíba. O Estado de Pernambuco foi representado pelo artista 
plástico Marcos Antônio Medeiros da Silva, da Faculdade José Lacerda Filho de Ciências Aplicadas - FAJOLCA, pelo professor Paulo Roberto de Andrade Gomes e pelo professor Silas Fernandes Pereira.

As apresentações da Região Norte foram coordenadas pela professora Eliana Marcolino, da Universidade Vale do Rio Doce, UNIVALE. O Estado do Amazonas foi representado pela professora Arleandra de Lima Ricardo. O Estado de Rondônia foi representado pelo professor Luciano Flávio de Oliveira, da Fundação Universidade Federal de Rondônia - UNIR, que neste momento do evento foi substituído pela professora Eliana Marcolino. Tocantins foi apresentado pelo professor Brenno Jadvas, do Instituto Federal de Tocantins.

A professora Patrícia Falco Genovez, da Universidade Vale do Rio Doce - UNIVALE coordenou as apresentações da Região Sul. O Paraná foi representado pela professora Camila Maciel de Oliveira, da Universidade Federal de Santa Catariana, UFSC; o Rio Grande do Sul foi representado pela professora Sônia Regina Shena Bertol, da Universidade de Passo Fundo - RS e pelo músico e folclorista Angelino Rogério.

A Região Sudeste foi moderada pela professora Sueli Siqueira, da Universidade Vale do Rio Doce - UNIVALE. O Estado do Espírito Santo foi representado pela professora Fabiana Campos Franco, da Faculdade Estácio de Sá de Vitória-ES e EMESCAM $^{3}$ e a professora Sátina Priscila Marcondes Pimenta, Faculdade Estácio de Sá de Vitória-ES e MULTIVIX. ${ }^{4}$ O Estado de Minas Gerais foi representado pela professora Eliana Marcolino, Universidade Vale do Rio Doce-UNIVALE. O Estado de São Paulo teve a representação da Mônica de Fátima Rodrigues Nunes Vieira, da Universidade de São Paulo-ECA/USP. Para encerrar as atividades deste turno a professora Sueli Siqueira apresentou um estudo sobre as relações entre Framingham e Governador Valadares, cidades irmãs, e explanou sobre o intenso processo emigratório da região valadarense e seus impactos no Brasil.

A comunidade brasileira compareceu para prestigiar a Feira Cultural e Científica: Brasil e Estados Unidos, concomitantemente a Rádio ABR A brasileira, fez ampla cobertura do evento. No mesmo dia, os professores fizeram lançamento de livros, conforme se pode ver no quadro abaixo:

\footnotetext{
${ }^{3}$ Escola Superior de Ciências da Santa Casa de Misericórdia de Vitória, do Espírito Santo.

${ }^{4}$ Grupo educacional Presencial e a Distância com sede no Espírito Santo.
} 
RELACult - Revista Latino-Americana de Estudos em Cultura e Sociedade

\begin{tabular}{|l|l|l|l|}
\hline Autor(a) & Obra & Editora & Data \\
\hline $\begin{array}{l}\text { Arleandra de Lima } \\
\text { Ricardo. In: Everaldo de } \\
\text { Oliveira Andrade (Org.) }\end{array}$ & $\begin{array}{l}\text { Os espiões da política do Pernambuco do } \\
\text { Serviço Especial Secreto e do Movimento de } \\
\text { Guerra. In: Brasil e América Latina na } \\
\text { Segunda Guerra Mundial, p. 65-100. }\end{array}$ & CRV & 2016 \\
\hline Edileila Portes & Rasgos na Alma: ode ao vale do rio Doce & $\begin{array}{l}\text { Atafona; Ateliê } \\
\text { Edileila Portes }\end{array}$ & 2017 \\
\hline $\begin{array}{l}\text { Eliana Marcolino; Dulce } \\
\text { Gil }\end{array}$ & Cartas pra Elas: Uma história de vida & Multifoco & 2016 \\
\hline Fabiana Campos Franco & Marina minha vida & EMESCAM & 2017 \\
\hline $\begin{array}{l}\text { Leda Gonçalves de } \\
\text { Freitas; Benedito } \\
\text { (Orgs.) }\end{array}$ & $\begin{array}{l}\text { Ser menina no Brasil contemporâneo } \\
\text { Patrícia Falco Genovez }\end{array}$ & $\begin{array}{l}\text { Inventário de Referências Culturais de } \\
\text { Governador Valadares }\end{array}$ & 2016 \\
\hline $\begin{array}{l}\text { Sandra Ferreira } \\
\text { Immigration and Psychology }\end{array}$ & UNIVALE & 2017 \\
\hline
\end{tabular}

A proposta da Feira era apresentar a cultura brasileira de maneira leve e cultural, e neste ritmo, no sábado à noite, os(as) participantes tiveram uma confraternização no Tropical Café onde dançaram, saborearam comidas típicas brasileiras no ritmo do som dos artistas brasileiros Pedro Coelho, Angelino Rogério e um show com Rafinha, músico brasileiro que vive nos Estados Unidos.

Assim como nos dias anteriores, o dia 05 de novembro foi muito esperado, os(as) professores(as)tiveram um workshop interativo na Harvard University. Metodologia "PreTexts", sobre intervenção de alfabetização precoce coordenado pela professora Doris Sommer. O que surpreendeu os(as) participantes foi saber que a metodologia adotada pela professora Sommer é uma releitura do Pedagogia do Oprimido de Paulo Freire e do Teatro do Oprimido do artista Augusto Boal, ambos brasileiros.

Esse momento foi digno de louvor pelo que foi planejado e executado pela professora Sommer, sua assessora e os participantes. Começou pela compreensão teórica embasada em Augusto Boal e Paulo Freire. Em seguida surpreendeu consequentemente a metodologia adotada de vivências lúdicas. O trabalho da professora é fundamentado no pressuposto de que a criatividade pode contribuir para mudanças sociais. Como proporcionar avanços sociais educando os cidadãos para tronarem-se sujeitos participativos e críticos. Sommer compreende que a arte é uma expressão humana que tem uma participação ímpar da formação da humanidade e por isso deve ser tratada com responsabilidade; princípio com o qual

\footnotetext{
${ }^{5}$ Com apoio da Comissão Mineira de Folclore.
} 
compartilhamos. Complementamos o raciocínio afirmando que a arte gera conhecimento, portanto, deve ser tratada como ciência porque transforma vidas e comunidades.

A renomada professora de literatura da Universidade de Harvard trabalha com a referência teórica de dois importantes brasileiros, a Pedagogia do Oprimido de Paulo Freire e, especificamente, o Teatro do Oprimido de Augusto Boal. Como Boal, ela parte do pressuposto de que a vivência artística nos traz aprendizagens para sairmos do discurso e aplicarmos o que aprendemos no cotidiano de nossas vidas. É a arte que é a propulsora das mudanças nas nossas vidas e, consequentemente, das transformações sociais. Daí percebe-se o valor pedagógico da arte, ou seja, as salas de aulas deixam de ser ambientes eminentemente teóricos, repetitivos, onde se copia e decora textos, para serem espaços interativos e criativos.

Certamente muitos dos presentes nunca tinham trabalhado com as ideias desses pensadores brasileiros e não conheciam seus princípios teóricos e suas ações práticas. Daí a importância histórica de sair do Brasil, ir à Universidade Harvard para vivenciar as teorias de Boal e Freire. É significativo ratificar que não foram apenas experiências, foram vivências. Um desencadear de concepções de mundo, de solidariedade, de respeito e de intercâmbio dentro da concepção de que a multiculturalidade é uma realidade porque as culturas são híbridas. Neste sentido o Brasil e os EUA têm muito em comum na economia, na indústria e no comércio, bem como na educação e na cultura.

No Brasil há o conceito popular no inconsciente coletivo, que nos leva a acreditar que tudo o que é bom vem ou é de fora. A Feira mostrou o contrário. Fomos à Harvard para uma vivência com uma professora mundialmente reconhecida pela importância do seu trabalho, que conhece profundamente os dois brasileiros que são referências no seu trabalho. Sommer afirma que "sem arte não se pode pensar em transformações sociais" (FLORES, 2017). Essa compreensão é fruto do pensamento de Boal. Quando do Workshop na Harvard, Sommer enfatizou o quanto é importante o papel da arte no desenvolvimento social; para ela "é indispensável, pois é o único lugar em que se pode divagar como forma de descobrir e obter conhecimento"; "a artista, diz ela, é a única que dará quatro respostas à mesma pergunta" (FLORES, 2017). Muitas vezes é necessário sair do Brasil para compreender que universidades como a Harvard, têm profissionais trabalhando com fundamentos teóricos de estudiosos brasileiros, que muitos brasileiros não conhecem e outros tantos rejeitam.

Nesse momento em que se tenta implantar no Brasil o projeto "escola sem partido" fomos surpreendidos em uma vivência na Harvard com uma professora que utilizando de 
teorias pensadas e experimentadas por teóricos brasileiros nos apresenta conceitos como: 1) trabalhar em grupo é somar conhecimentos; 2) um método baseado na cultura popular é um método que conscientiza e politiza. De fato, foi-nos apresentado o método da palavra geradora de Paulo Freire que parte do pressuposto de que a educação deve ser uma prática libertadora.

Os livros de Augusto Boal, assim como os de Paulo Freire foram traduzidos para dezenas de idiomas. Então o "produto" intelectual brasileiro rompe fronteiras, fortalece outras culturas e ratifica a tese da cultura híbrida e da multiculturalidade. Afinal o Brasil é um país de múltiplas culturas ou não?

Para encerrar as atividades foi realizada uma visita técnica ao Massachusetts Institute of Technology - MIT, coordenada por Rosabelli Coelho-Keyssar, gestora do Programa MITBrazil no Massachusetts Institute of Technology. Os(as) convidados(as) conheceram um pouco do maior Instituto de Tecnologia dos Estados Unidos. A visita fora guiada pelo jovem estudante brasileiro Allan Costa, 18 anos, de Bauru-SP. Ele é um grande embaixador do MITBrazil Program. Em junho de 2019, receberá o título de "Bachelor of Science in Computer Science and Engineering; Minor in Statistics and Data Science". O jovem guiou o grupo de visitantes pelos labirintos do MIT, mostrou laboratórios e falou um pouco sobre o funcionamento daquele centro de pesquisas em tecnologias. Além do mais, apresentou algumas curiosidades como o anel que os estudantes recebem ao entrar no MIT; o anel contém o mapa da instituição para o aluno não se perder dentro do instituto. A visita foi muito proveitosa e o contato com Rosabelli e Alan Costa nos fez entender que o Brasil tem grandes mentes pensantes, entretanto o problema é que esses cérebros não são valorizados em nosso país como deveriam.

\section{Avaliação do evento}

Após a visita, nos reunimos em uma sala onde foi feita a avaliação do evento. Os participantes tiveram a oportunidade de relatar os pontos positivos, negativos e apresentaram sugestões para outra edição da Feira.Vamos descrever os comentários da avaliação, sem citar nomes. Foi utilizada a técnica de avaliação: Que bom! Que pena! Que tal? Seguem-se os resultados:

Que boa esta iniciativa; que bom criar possibilidades de relacionamentos; que bom estar com este grupo; que bom que o conhecimento da academia seja compartilhado com a comunidade; que boa oportunidade de conhecer as pessoas; oportunidade de fazer um curso 
na Harvard; que o evento foi concretizado; sonhos se tornaram realidade; que bom que foi criado um embrião.

Na sequência foram destacadas as fragilidades respondendo ao quesito que pena: que o evento não conseguiu agradar a todos; não envolver mais gente da comunidade brasileira; que a programação foi ampla demais; foi muito cansativo; que o tempo não fora ajustado para contemplar horário de almoço; ausência de curadoria para as obras de artes; concentração de tarefas nas mãos dos organizadores; escassez de recursos.

Para finalizar, foram apresentadas sugestões na forma: Que tal? A inclusão de mais americanos(as) na feira; fazer mais parcerias; explorar espaços mais acessíveis para a comunidade brasileira, dividir melhor o tempo, levar em consideração as diferenças do fuso horário para não sacrificar quem veio do Brasil, pensar na alimentação; principalmente no horário de almoço, artistas do Brasil e estudantes de artes dos Estados Unidos fazerem intervenções urbanas, começar a programar a Feira com uma comissão organizadora, criar um comitê da academia e de artes, dar continuidade ao projeto, buscar mais recursos, menos sobrecarga de trabalho e mais workshop, buscar mais patrocinadores, pensar em um produto desta Feira, criar espaço para lazer e espaço para folclore.

Dos pontos positivos, o destaque foi para a iniciativa do projeto; quinze pessoas salientaram que foi muito boa a iniciativa. Para os pontos frágeis, ressalta-se a precariedade da dinâmica de gerenciamento do tempo. Sete participantes ressaltaram que a agenda ficou sobrecarregada; isso tornou o evento cansativo, além de não ter sido reservado horário de almoço. Quanto às sugestões, elas se concatenam com as fragilidades; a proposta é que o tempo seja melhor gerenciado. Sobre a má distribuição do tempo, ressalta-se que o evento fora pensado nos padrões americanos, com base na cultura americana quando o almoço acontece bem tarde entre $15 \mathrm{~h}$ e $16 \mathrm{~h}$, porém a diferença do fuso horário entre Brasil e Estados Unidos na época da Feira era de três horas, ou seja, se o almoço fosse servido às $15 \mathrm{~h}$ no horário americano, correspondia às $18 \mathrm{~h}$ do horário brasileiro; realmente foi sacrificante. A agenda muito arrojada, uma atividade na sequência da outra, provocou estresse e cansaço nos participantes.

\section{Notas e reflexões finais}

O evento foi pensado, planejado executado em um curto espaço de tempo, ou seja, em menos de um ano. O primeiro encontro da professora Eliana Marcolino com a empresária 
Ilma Paixão aconteceu em janeiro de 2017. Nesse mês, as primeiras ideias foram colocadas no papel e o diálogo continuou por meio das redes sociais, mais precisamente pelo WhatsApp. No mês de julho de 2017, a professora Marcolino retornou aos Estados Unidos para continuar o planejamento da Feira que já estava prevista para ser realizada no mês de novembro do mesmo ano. Na época, a maioria dos(as) professores(as) brasileiros(as) havia sido convidada a participar do evento, e as coordenadoras aguardavam a confirmação dos mesmos.

A equipe de participantes brasileiros que saiu do Brasil para realizar a Feira foi composta pelos representantes dos referidos Estados: Amapá: Romualdo Palhano, Doutor em Artes da Universidade Federal do Amapá. Brasília: Lêda Gonçalves de Freitas, Doutora em Psicologia, da Universidade Católica de Brasília e o artista plástico Josafá Neves. Espírito Santo: Fabiana Campos Franco, Doutora em Comunicação Social e Sátina Priscila Marcondes Pimenta, Mestre em Administração, ambas da Faculdade Estácio de Sá. Mato Grosso do Sul: Rosângela Lieko Kato, Mestre em Direito e Economia, Universidade Federal de Mato Grosso do Sul. Minas Gerais contou com a maior delegação composta pelos professores da Universidade Vale do Rio Doce - UNIVALE: Eliana Marcolino, Doutora em Comunicação Social e coordenadora da Feira; Sueli Siqueira, Doutora em Sociologia e Política; Terezinha Vilarino, Doutora em História. Patrícia Falco Genovez, Doutora em História; Pedro Marçal, Doutor em Ciências Biológicas; Edileila Portes, Mestre em Gestão Integrada do Território e artista plástica; Vinícius Cabral, Mestre em Gestão Integrada do Território; Pedro Coelho, músico. Paraíba: Carlos José Cartaxo, Doutor em Artes Visuais, Universidade Federal da Paraíba; Pernambuco: Marcos Medeiros, Artista Plástico, FAJOLCA; Silas Fernandes Pereira, Bacharel em Teologia; Paulo Roberto de Andrade Gomes, Mestre em Administração. Os três professores de Pernambuco são representantes da Faculdade José Lacerda Filho de Ciências Aplicadas, FAJOLCA. Rio Grande do Sul: Sônia Regina Shena Bertol, Doutora em Comunicação Social, professora da Universidade de Passo Fundo; Angelino Rogério, músico folclorista. São Paulo: Mônica de Fátima Rodrigues Nunes, Doutora em Comunicação Social, ECA/USP. Tocantins: Brenno Jadvas, Mestre em Artes Cênicas, professor do Instituto Federal de Tocantins. Um total de 22 participantes entre professores, artistas plásticos e músicos.

Da experiência na Universidade Harvard resgatamos o valor da pesquisa e dos pensadores brasileiros, pois enquanto no Brasil segmentos da política tentam instituir "a escola sem partido" que desumaniza a educação, querendo dissociar a educação do cotidiano social, a Harvard trabalha focando no contrário, ou seja, nos fundamentos da arte para 
enfrentar os desafios sociais. Doris Sommer, como milhares de professores (as) brasileiros/as, trabalha com a perspectiva de levar a humanidade a abraçar o compromisso com o mundo mais justo e solidário.

Poucas pessoas sabem que Augusto Boal foi convidado a ministrar oficinas na Harvard e que do seu trabalho muitos desdobramentos aconteceram. Doris Sommer no segundo capítulo do seu livro A Obra de Arte no Mundo: Agência Cívica e Humanidades Públicas informa que Augusto Boal foi convidado pela Harvard para coordenar oficinas e trabalhar suas técnicas para participantes e estudantes. As oficinas tiveram efeitos e resultados múltiplos; por exemplo, a produção teatral de verão em uma escola secundária local resultou em uma abordagem do Fórum de Teatro dirigida para a prevenção e tratamento da AIDS para jovens na Tanzânia. Vários outros projetos de agentes de mudança foram desenvolvidos e tiveram resultados brilhantes como a campanha, dos anos 80 aos anos 90, com foco nos direitos dos homossexuais em Nova York. O resultado do impacto desse trabalho foi a redução dos custos do tratamento de AIDS e a agilidade e eficiência do seu tratamento.

Nesse sentido, a Feira Cultural e Científica: Brasil e Estados Unidos teve uma importância ímpar para os participantes, brasileiros e norte-americanos, envolvidos direta e indiretamente, o que corresponde a acreditarmos que uma segunda edição faz-se necessária para que, dessa vez, nós professores (as) brasileiros (as), possamos proferir oficinas em escolas, faculdades e centro comunitários, além de inúmeras outras atividades que podem ser desenvolvidas.

A Feira Cultural e Científica: Brasil e Estados Unidos é de grande relevância para a comunidade brasileira que vive nos Estados Unidos. Lamentamos a avaliação do CNPQ, que não viu o projeto como relevante. Ressaltamos que a arte e a cultura são importantes para o enfrentamento da solução de questões sociais.

\section{Referências}

BOAL, Augusto. 200 exercícios e jogos para o ator e não ator com vontade de dizer algo através do teatro. Rio de Janeiro: Civilização Brasileira, 1977.

CANCLINI, Néstor García. Culturas híbridas: Estratégias para entrar e sair da modernidade. São Paulo: EDUSP, 1998.

FLORES, Gabriel, "Sin arte no se puede pensar en cambios sociales". El Comercio,

Tendencias-Cultura, Quito, 12 mai, 2017. 
http://www.elcomercio.com/tendencias/dorissommer-arte-sociedad-charlauniversidadandinasimonbolivar.html Acesso em: 20 de jul. 2018.

FREIRE, Paulo. Pedagogia do Oprimido. São Paulo: Paz e Terra, 1988.

SOMMER, Doris. The Work of Art in the World: Civic Agency and the Public Humanities. Durham: Duke University Press, 2014. 